\title{
Adjunctive drinking during variable and random-interval food reinforcement schedules
}

\author{
J. R. MILLENSON, ROBERT B. ALLEN, and STEVEN PINKER \\ McGill University, Montreal, Quebec, Canada
}

\begin{abstract}
Rats were trained to leverpress for food and subsequently exposed to either arithmetic series or random variable-interval reinforcement schedules. Adjunctive drinking developed in all subjects exposed to arithmetic variable-interval reinforcement, but did not develop in six of the eight animals trained on the random schedule. The results suggest that adjunctive drinking is the result of an interaction between the tendency of rats to drink after eating and the ability of locally low probabilities of reinforcement within schedules to induce conditioned behavioral states.
\end{abstract}

Attempts to explain the excessive drinking shown by rats and other species under schedules of intermittent food presentation have appealed to adventitious reinforcement (Segal, 1969), dry-mouthproduced thirst (Lotter, Woods, \& Vasselli, 1973), and frustration reduction (Kissileff, 1973). Adventitious reinforcement is now considered an unlikely explanation because of the failure of programmed contingencies separating drinking from pellet delivery to prevent the development or disrupt the maintenance of drinking (Falk, 1969; Segal \& Oden, 1969), and because the temporal properties of the induced drinking show it to be a postfood, rather than a prefood, phenomenon (King \& Schaeffer, 1973). The possibility that excessive drinking results from a tendency of animals to take a drink after every dry food presentation is ruled out by the absence of such drinks on continuous reinforcement (CRF) schedules (Keehn, 1972), and by the systematic variation of drink duration and probability with the magnitude and frequency of food delivery (Flory, 1971; Millenson, 1975; Segal, Oden, \& Deadwyler, 1965). Frustration reduction must be regarded as still largely speculative, since its empirical measurement continues to present numerous unsolved problems.

Falk $(1969,1971)$ and Staddon and Simmelhag (1971) developed another explanation for scheduleinduced drinking. They supposed it to be an instance of a broader class of behavior (adjunctive or interim) induced by the low probability of reinforcement

\footnotetext{
This research was supported by grants from the National Research Council (Canada) and the Fundacào de Ampara à Pesquisa do Estado de Sao Paulo (Brazil) to J.R.M. We are indebted to Jill Sharpe and Paula Pasquali for valuable comments and encouragement. S. Pinker is now at the Department of Psychology and Social Relations, Harvard University. Address reprint requests to Robert B. Allen, whose present address is: Department of Psychology, C-009, University of California, San Diego, La Jolla, California 92093.
}

existing immediately after reinforcement on certain reinforcement schedules. In this formulation, the interfood behaviors of drinking, aggression, and wood gnawing (Killeen, 1975) in the rat and attack, wing flapping, and various repetitive activities in the pigeon are all manifestations of an identical behavioral state (Staddon, 1977). The common inducing operation of this state, relatively low probability of reinforcement, is, however, not as simple or as unambiguous as it might at first appear. In fixed-interval (FI) and fixed-ratio (FR) schedules, the probability of reinforcement immediately after a reinforcement is certainly low. But on variableinterval (VI) schedules, reinforcers can be programmed in a wide variety of distributions, and there is a certain indeterminancy in the meaning of a "low probability of reinforcement."

Schedule-induced drinking (Clark, 1962; Falk, 1967; King \& Schaeffer, 1973), attack (Dove, Rashotte, \& Katz, 1974), and wing flapping (Staddon \& Simmelhag, 1971) have been observed on VI schedules. On the basis of such observations, Staddon (1977) concluded that periods either of low reinforcement probability within a given schedule or a low but constant reinforcement probability throughout a given schedule can induce adjunctive behavior. But how a uniform probability of reinforcement in time, regardless of its absolute value, could differentially control behavior at different times remains unclear.

This paradox may, however, be more apparent than real. The VI schedules which have been used to induce interim behavior contain substantial departures from the ideal postreinforcement constancy of reinforcement probability. Schedule-induced behavior has not been examined under a truly random-interval (RI) schedule (Millenson, 1963) where the reinforced (or terminal) behavior would be expected to occur at a constant probability throughout the interreinforcement interval (cf. 
Catania \& Reynolds, 1968, Figures 11 and 12). If adjunctive behavior is, at least in part, due to relatively low local probabilities of reinforcement, such schedules should show only low levels of adjunctive behavior.

\section{EXPERIMENT 1}

\section{Method}

Subjects. Eight experimentally naive adult male albino rats, initially weighing between 375 and $425 \mathrm{~g}$, served as subjects. The animals were housed individually in an environmentally controlled room and maintained at $80 \%$ of their free-feeding weights by postsession supplements of Purina Lab Chow. Water was freely available at all times in their home cages.

Apparatus. Four standard two-lever Campden Instruments CI410 rodent test chambers were mounted in ventilated, soundattenuating enclosures. Only the right lever was functional in this experiment. Reinforcers consisted of $45-\mathrm{mg}$ Noyes rat pellets. A calibrated Richter tube, modified by the addition of a metal spout, was clipped to the right side wall of each chamber where it was accessible for licking through a hole drilled $5 \mathrm{~cm}$ above the grid floor. Licks were detected by drinkometer circuits. Leverpresses and licks were monitored by cumulative response recorders and by a PDP 11/05 computer which also controlled the contingencies and summarized the data.

Procedure. The rats were assigned to one of two groups, RI or VI, roughly matched for body weights. Throughout the experiment, two rats of each group ran concurrently in 1-h daily sessions. The animals were shaped to press the right lever for pellets and then given five sessions of CRF. Three sessions of RI or VI $10-\mathrm{sec}$ followed, and two subsequent sessions of RI or VI 30-sec completed preliminary training.

The drinking tubes, which had been absent during these 10 sessions of preliminary training, were then installed, and 25 daily sessions of RI $60-\mathrm{sec}$ or VI $60-\mathrm{sec}$ were run. The lengths of the intervals of the RI 60 schedule were determined by a hardware random-number generator (Millenson \& Sullivan, 1969). Reinforcement assignments were made every $0.93 \mathrm{sec}(\mathrm{t})$ with a probability (p) of .0156. Assignments were not queued, but each one remained in effect until claimed by a leverpress. This method defines an RI schedule whose mean $(\mathrm{t} / \mathrm{p})$ is approximately $60 \mathrm{sec}$ $(59.73 \mathrm{sec})$, and whose intervals approach the exponential distribution (cf. Millenson, 1963). The values and ordering of the intervals composing the VI schedule were taken from Falk (1967). The average length of the 13 intervals $(100,5,56,50,68,12,109$, $80,20,120,40,90$, and $30 \mathrm{sec}$ ) was $60 \mathrm{sec}$.

\section{Results}

Both schedules succeeded in generating reinforcement rates close to the nominal 60 reinforcements/ average of a VI 60 -sec schedule. The obtained average hourly rate of reinforcement for the RI schedule was 56.5 (range 55.1-60.2), and that of the VI schedule 55.6 (range 54.3-56.5).

Figure 1 shows the within-session water consumption for the rats over the course of the 25 experimental sessions. Initial-session water consumption ranged from 3 to $9 \mathrm{ml}$. Thereafter, the VI rats (right panel) progressively increased their daily intakes, so that by the end of the experiment they were drinking from two to seven times their initial amounts. In contrast, three of the four RI rats showed no tendency to increase their initial water consumption.

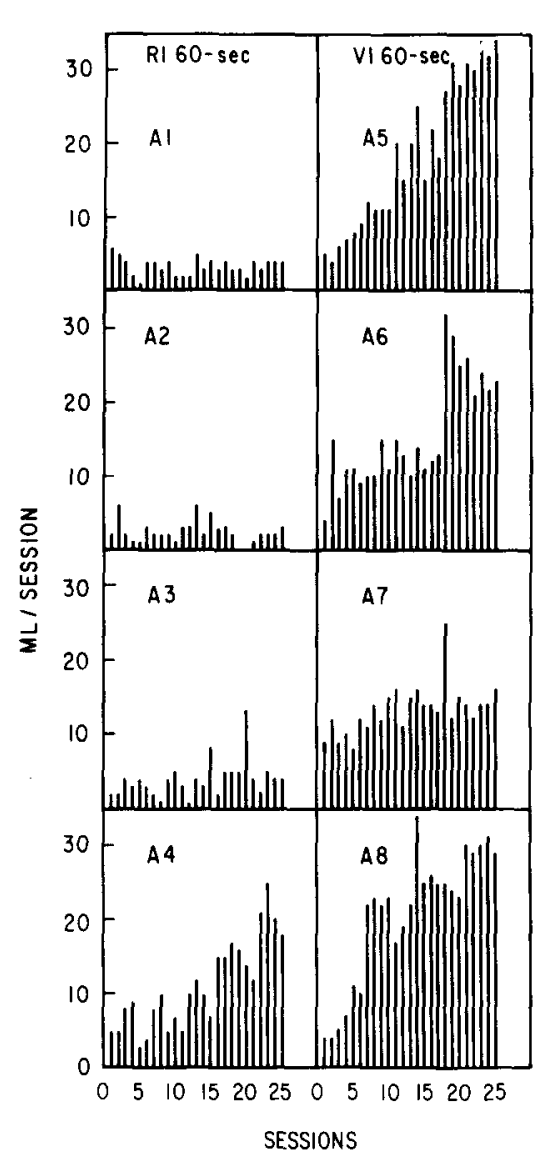

Figure 1. Water intake (ml/hourly session) for each of the 25 experimental sessions in Experiment 1, plotted individually for each rat. (A leak in A2's water tube resulted in loss of data for Sessions 19 and 20.)

Only A4 in the RI group developed a degree of polydipsia.

Lick rates followed a course of acquisition which closely paralleled the changes in water consumption. As the dots in Figure 2 indicate, all VI rats and A4 in the RI group progressively increased the number of licks per reinforcement over the course of the experiment. On the other hand, the schedule-dependent behavior, shown in Figure 2 as leverpresses per pellet (connected lines), remained unchanged for the VI animals, and for A3 and A4 in the RI group as well. However, A2 and perhaps A1 in the RI treatment did tend to increase their leverpressing as training progressed.

Neither the drinking nor the leverpressing that these schedules engendered was distributed equally throughout the postpellet times. Rather, as Figure 3 indicates, drinking, in those animals that did become polydipsic, was mainly confined to the $10-20 \mathrm{sec}$ postreinforcement period. Given that a rat became polydipsic, this pattern of drinking did not seem to depend on the type of schedule. Thus, A4 who became a drinker while working on RI, also shows the 
characteristic postpellet drinking common to all the VI animals. Compare this pattern with the very occasional drinking of the remaining three RI animals, which were as likely to drink at any one postreinforcement time as another.

The patterns of leverpressing (Figure 3 ) produced by the two schedules were quite different. For the first $20 \mathrm{sec}$ after a reinforcement, leverpress rates were extremely low, sometimes zero, in VI rats. Thereafter, the rates of pressing increased as time from the last reinforcement elapsed. This dependence of leverpressing on postreinforcement time in VI rats contrasts markedly with rats A2 and A3 in the RI group. These rats did exhibit low postpellet leverpressing rates for the first $10 \mathrm{sec}$ after reinforcement, but thereafter they responded at a constant rate throughout the remainder of the interreinforcement interval. The constant slope of the cumulative leverpressing records of RI animals confirmed that this uniform response pattern was not an averaging artifact. The behavior of rat A4 appeared to be a composite of RI and VI patterns. Like animals on the VI, subject A4's immediate postreinforcement rate of leverpressing was low for 20 or $30 \mathrm{sec}$, while his

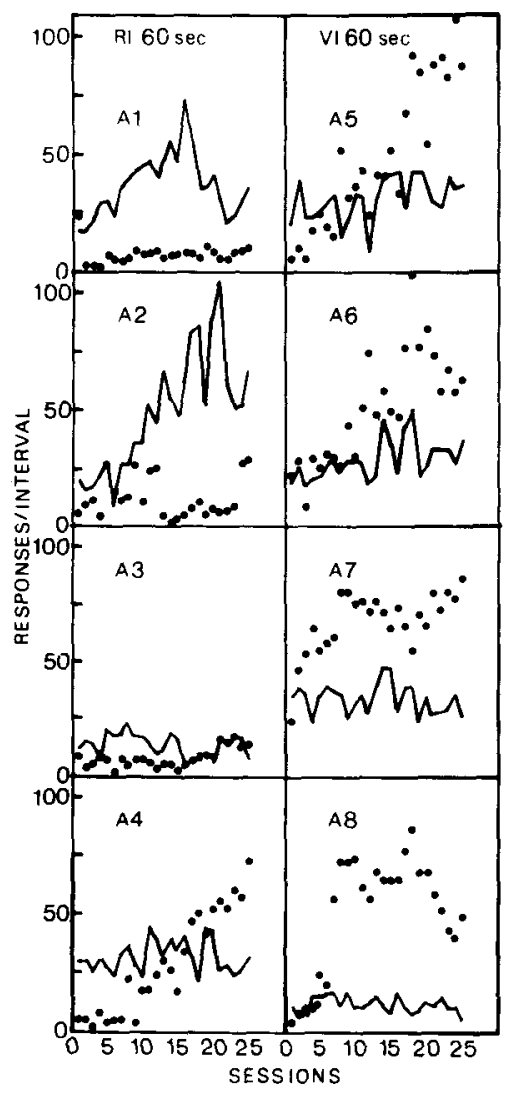

Figure 2. Mean barpresses (connected lines) and licks (dots) per mean interreinforcement interval over the course of 25 experimental sessions, plotted individually for each rat.

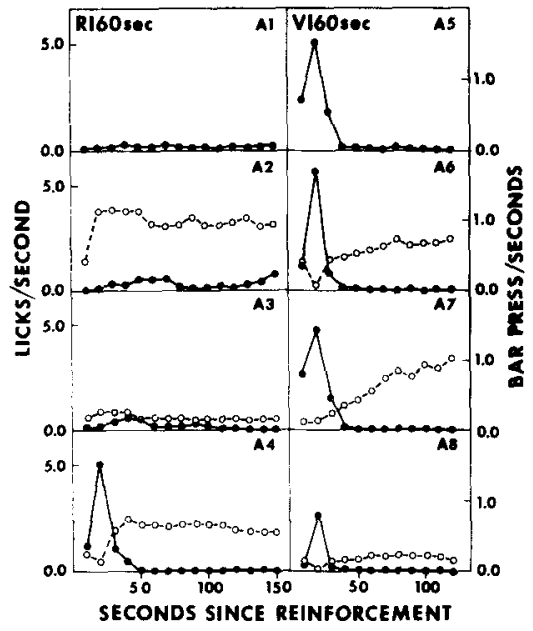

Figure 3. Mean rates of barpressing (open circles) and licking (solid dots) in progressive 10 -sec-wide postreinforcement time bins, averaged over the last three sessions in Experiment 1. Note: Because there were more opportunities for reinforcements at early postreinforcement times, more data generally contributed to the averages at early postreinforcement times. (Computer core memory was insufficient to permit the collection of barpresses data from the chamber in which A1 and A5 ran.)

lick rate was high. Thereafter, A4 pressed at a uniform rate, like the other RI animals, who did not become drinkers.

\section{EXPERIMENT 2}

In order to assess how idiosyncratic the performance of rat A4 was, four experimentally naive hooded adult male rats $(\mathrm{H} 1, \mathrm{H} 2, \mathrm{H} 3, \mathrm{H} 4)$ were given 25 to 30 sessions on the RI $60-\mathrm{sec}$ schedule. The pretraining, apparatus, and procedure were the same as for the RI group in Experiment 1.

\section{Results}

Figure 4 shows water intake by the rats during Experiment 2. The median value of session water intake for the first five sessions of RI training was $8.5 \mathrm{ml}$ (range 4-16), and for the last five sessions, $9.5 \mathrm{ml}$ (range 4-17.5). From the time the water was introduced in Experiment 2, the levels of water intake were slightly higher than observed for the RI group in Experiment 1. However, only rat $\mathrm{H} 2$ showed any indication of any systematic increase in its drinking and a more marked increase in its licking over sessions. This rat's first and last 5-day medians of water intake were 7.5 and $12.5 \mathrm{ml}$, respectively, with only one overlapping observation. Lick rates for $\mathrm{H} 2$ quadrupled from an initial rate of 15 licks/pellet to 60 licks/pellet by the end of training. The remaining three rats showed no tendency to increase either their water consumption or their lick rates over the course of the experiment, and in other 


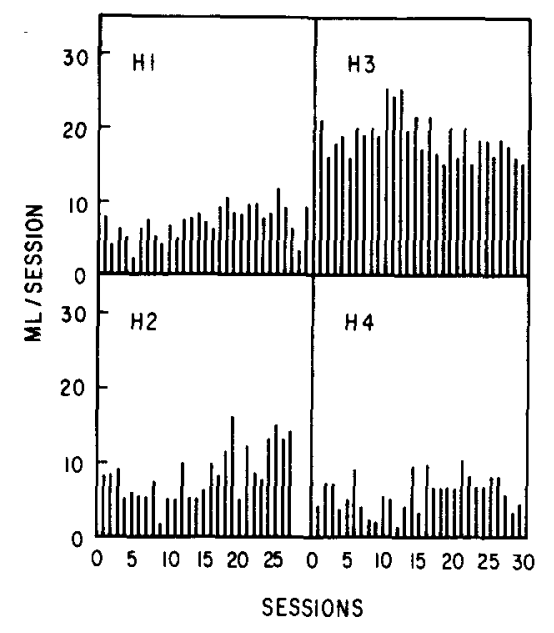

Figure 4. Water intake ( $\mathrm{ml} / \mathrm{session})$ for each of the subjects during Experiment 2.

respects, their behavior paralleled the results of Experiment 1.

\section{DISCUSSION}

The pattern of reinforced leverpressing that developed on the arithmetic series VI and RI schedules of the present experiments was similar to the pattern of keypecking of pigeons previously reported for these schedules (Catania \& Reynolds, 1968; Millenson, 1963). Both schedules produced low rates of instrumental (terminal) responding (immediately after reinforcement). On VI, these rates rose gradually throughout the postreinforcement period. On RI, rate of barpressing was low for a brief time after reinforcement. Thereafter, it resumed abruptly at a moderate value which was sustained until the delivery of the next reinforcement. These rates of leverpressing closely mirrored the probabilities of reinforcement in the two schedules, which also began low under the VI schedule and rose throughout the interreinforcement interval, and which remained fixed at a constant value under the RI schedule.

Under the VI schedules, all rats acquired typical adjunctive drinking (Falk, 1967, 1969, 1971) that increased in magnitude over the course of the experimental sessions, but was confined principally to a period 10-20 sec after food delivery. Presumably the rats spent a substantial portion of the first $10 \mathrm{sec}$ following food delivery consuming the food pellet. Thus, the rates of licking and leverpressing are somewhat distorted in comparison to the later time bins. Nevertheless, for most of the polydipsic rats, the lick rates were elevated in the first time bin. This behavior thus had many of the characteristics reported for drinking when it occurs as an interim activity on food schedules (Killeen, 1975; Staddon \& Ayres, 1975). However, since the mean leverpress rates of rats under the VI remained unchanged throughout the course of training, their terminal and interim activities did not develop together, as they do under most periodic schedules (cf. Staddon \& Ayres, 1975).

In contrast to the consistent adjunctive drinking generated by the VI schedules, under the RI food schedules the drinking in six of eight rats studied appeared not to be polydipsic. These animals were drinking no more water at the end of 25 to 30 hourly sessions on RI 60-sec food schedules than they were at the very beginning of training. The small amounts of water they drank throughout RI training were comparable to the 7 to $9 \mathrm{ml}$ that 23 -h fooddeprived rats normally drink when given an hour's free feeding of Noyes food pellets (Dickenson, 1973; Fitzsimons \& Le Magnen, 1969; King \& Schaeffer, 1973). Although the possibility cannot be ruled out that with more sessions eventually even these RI rats might have developed interim drinking, the lack of any systematic upward trends in either their drinking or licking makes this seem unlikely. Elsewhere it has been shown that schedule-induced drinking under VI 60-sec and similar schedules generally is asymptotic by 10 to 15 sessions (e.g., King \& Schaeffer, 1973; Sanger \& Blackman, 1975; Segal, 1965).

VI schedules have been found to generate and maintain adjunctive drinking in rats (Falk, 1967) and wing flapping, repetitive locomotor movements (Staddon \& Simmelhag, 1971), and attack (Dove, Rashotte, \& Katz, 1974) in pigeons. However, those VI schedules provided gradients of differential postreinforcement probability of reinforcement. For instance, Falk's extensive observations were made with arithmetic series VIs. Staddon and Simmelhag's VI 8-sec schedule was a linear VI (cf. Catania \& Reynolds, 1968). In both of these types of VIs, the probability of reinforcement is low immediately following a reinforcement, and rises monotonically throughout the post-reinforcement period. Dove et al. (1974) used a Fleshler-Hoffman (1962) distribution which does approximate a random schedule with constant postreinforcement probability of reinforcement. However, the pigeons of Dove et al. attacked only at schedule values that possessed appreciable $(15$ or $30 \mathrm{sec}$ ) minimum interreinforcement intervals in which the probability of food was zero. Apparently, the VI schedules for which adjuncts have been reported had discriminable (cf. Catania \& Reynolds, 1968) gradients of reinforcement probability, and hence contained periods of locally low probability of reinforcement that the theories of Falk $(1969,1971)$ and Staddon and Simmelhag (1971) imply are necessary to induce adjunctive activities.

Two of the present eight rats exposed to RI contingencies did develop increased lick rates, and in one (A4), water intake was sufficiently elevated at the end of 25 sessions to be termed excessive. The temporal 
location of the adjunctive drinking of these two rats also bore a strong resemblance to the location of the drinking of VI rats. These contingencies, observed under what otherwise were apparently very unfavorable conditions for the development of adjunctive behavior, suggest that two processes interact in the induction of adjunctive drinking. One of these processes is simply the strong tendency in some species, rats included, to drink after eating (Kissileff, 1969). When this process is absent or weak, as it is in hamsters and gerbils, we should not expect food schedule-induced drinking, and indeed none occurs (Wilson \& Spencer, 1975). The tendency of rats and some other animals to drink after eating combines, under some reinforcement schedules, with another process: the tendency of locally low probabilities of reinforcement to induce a classically conditioned state (Staddon, 1977). Such a state arises by temporal conditioning within FI and many VI schedules because in these schedules the time immediately after the delivery of a food pellet (CS -) bears a negative correlation with reinforcement (US + ). The actual behavioral manifestations of such states will, however, not be invariant, but will depend upon the species, the reinforcer, and the environmental supports (Staddon, 1977). When we present food to food-deprived rats on such interval schedules and make a water bottle available, we optimize the conditions for excessive drinking. But in other food schedules, such as CRF and the present RI schedules, that lack reinforcement probability gradients, such classically conditioned states are absent. These schedules favor the immediate resumption of schedule-dependent (instrumental) behavior after eating, and this process competes with the eat-drink tendency that rats possess. Here the outcome must depend on factors which differentially affect the strength of the two competing tendencies. Some of these factors might be ontogenic, such as level of motivation or overall average density of reinforcement; but others are probably phylogenetic and express themselves in individual differences.

This account makes quite specific predictions about when and where to expect adjunctive drinking in most reinforcement schedules. Also, by calling attention to the inducing properties of local temporal gradients of reinforcement, it suggests that manipulations in these gradients may modulate patterns of adjunctive behavior conditioned on other schedules. The account suggests that any manipulation affecting the strength of the CS - -US + association ought to have a strong influence on adjunctive drinking. Therefore, the power of temporal intervals to induce classically conditioned states that include adjunctive behaviors should be affected by any informational variation in their prediction of non-reinforcement, regardless of the absolute probability of reinforcement associated with them.

\section{REFERENCES}

Catania, A. C., \& Reynolds, G. S. A quantitative analysis of the responding maintained by interval schedules of reinforcement. Journal of the Experimental Analysis of Behavior, 1968, 11, 327.383.

CLARK, F. C. Some observations on the adventitious reinforcement of drinking under food reinforcement. Journal of the Experimental Analysis of Behavior, 1962, 5, 61-63.

Dickenson, A. Prandial drinking following septal lesions in rats. Physiology and Behavior, 1973, 10, 335-338.

Dove, L. D., Rashotte, N. E., \& KATz, H. N. Development and maintenance of attack in pigeons during variable-interval reinforcement of key pecking. Journal of the Experimental Analysis of Behavior, 1974, 21, 563-569.

FALK. J. L. Control of schedule-induced polydipsia: Type, size, and spacing of meals. Journal of the Experimental Analysis of Behavior, 1967, 10, 199.206.

FALK, J. L. Conditions producing psychogenic polydipsia in animals. Annals of the New York Academy of Sciences, 1969, 157, 569-593.

FALK, J. L. The nature and determinants of adjunctive behavior. Physiology and Behavior, 1971, 6, 577-588.

Fitzsimons, J. T., \& Le Magnen, J. Eating as a regulatory control of drinking in the rat. Joumal of Comparative and Physiological Psychology, 1969, 87, 273-283.

FleshleR, M., \& Hoffman, H. S. A progression for generating variable-interval schedules. Journal of the Experimental Analysis of Behavior, 1962, 5, 529-530.

Flory, R. K. The control of schedule-induced polydipsia: Frequency and magnitude of reinforcement. Learning and Motivation, 1971, 2, 215-227.

KEEHN, J. D. Schedule-dependence, schedule-induction, and the law of effect. In R. M. Gilbert \& J. D. Keehn (Eds.), Schedule effects: Drugs, drinking, and aggression. Toronto: University of Toronto Press, 1972.

KILleen, P. On the temporal control of behavior. Psychological Review, 1975, 82, 89-115.

King, G. D., \& SChaEffer, R. W. Developmental analysis of schedule-induced polydipsia. Psychological Reports, 1973, 32, 1087-1095.

KISSILEFF, H. R. Food-associated drinking in the rat. Journal of Comparative and Physiological Psychology, 1969, 67, 284-300.

KIssilefF, H. R. Nonhomeostatic controls of drinking. In A. N. Epstein, H. R. Kissileff, \& E. Stellar (Eds.), Neuropsychology of thirst. Washington, D.C: Winston, 1973.

LOTTER, E. C., Woods, S. C., \& V AsselLI, J. R. Schedule-induced polyd ipsia: An artifact. Journal of Comparative and Physiological Psychology, 1973, 83, 478-484.

Millenson, J. R. Random interval schedules of reinforcement. Journal of the Experimental Analysis of Behavior, 1963, 6, 437-443.

Millenson, J. R. The facts of schedule-induced polydipsia. Behavior Research Methods \& Instrumentation, 1975, 7, 257-259.

Millenson, J. R., \& Sullivan, G. D. A hardware random number generator for use with computer control of probabilistic contingencies. Behavior Research Methods \& Instrumentation, $1969,1,194-196$.

Sanger, D. J., \& Blackman, D. E. The effects of chlordiazepoxide on the development of adjunctive drinking in rats. Quarterly Journal of Experimental Psychology, 1975, 27, 499-505.

SEGAL, E. F. The development of water drinking on a dry-food free-reinforcement schedule. Psychonomic Science, 1965, 2 29-30.

SEGAL, E. F. Transformation of polydipsic drinking in to operating drinking: A paradigm? Psychonomic Science, 1969, 16, 133-134

SEGAL, E. F., \& ODEN, D. L. Schedule-induced polydipsia: Effects of providing an ultimate reinforced response and of introducing a lick-contingent delay in food delivery. Psychonomic Science, 1969, 15, 153-154.

Segat, E. F., Oden, D. L., \& Deadwyler, S. A. Determinants of 
polydipsia: IV. Free-reinforcement schedules. Psychonomic Science, 1965, 3, 11-12.

Staddon, J. E. R. Schedule-induced behavior. In W. K. Honig \& J. E. R. Staddon (Eds.), Handbook of operant behavior (Vol. II). New York: Prentice-Hall, 1977.

Staddon, J. E. R., \& Ayres, S. L. Sequential and temporal properties of behavior induced by a schedule of periodic food delivery. Behaviour, 1975, 54, 26-49.

Staddon, J. E. R., \& Simmelhag, V. L. The "superstition" experiment: A re-examination of its implications for the principles of adaptive behavior. Psychological Review, 1971, 78, 3-43.

Wilson, S., \& SPEnCER, W. B. Schedule-induced polydipsia: Species limitations. Psychological Reports, 1975, 36, 863-866.

(Received for publication December 2, 1976; accepted March 29, 1977.) 